\title{
Educación popular con niñxs. Diálogos entre la pedagogía del oprimido y la pedagogía de la ternura
}

Fecha de recepción: 28 de marzo de 2020.

Fecha de aceptación: 2 de junio de 2020.

\section{Resumen}

A partir de un breve análisis del Estado capitalista como relación social y de la conceptualización de la niñez como minoría en situación de opresión, iniciamos el artículo preguntándonos en torno a la forma de socialización capitalista que se condensa en la institucionalidad estatal y aloja en sí la producción y reproducción de vínculos intergeneracionales marcados por una forma de violencia específica: el adultismo. Posteriormente, analizamos las nociones freireanas de opresión y educación bancaria desde el cruce con perspectivas críticas del adultismo, para luego preguntarnos cómo desarrollar pedagogías emancipatorias centradas en el diálogo si en nuestras sociedades lxs niñxs no son consideradxs interlocutorxs válidxs. Para ensayar respuestas posibles, proponemos un cruce entre la pedagogía del oprimido y la pedagogía de la ternura. Desde allí, invitamos a asumir los desafíos de la formación y la organización política de las nuevas generaciones, promoviendo su protagonismo, y buscando reinventar las pedagogías que contribuyan a la construcción de proyectos emancipatorios desde una solidaridad niña, organizada y de clase. Pretendemos con este artículo realizar un aporte a la teoría y la práctica pedagógicas desde la especificidad de la educación popular con niñxs.

Palabras clave: educación popular; niñez; adultocentrismo; participación; ternura. 


\title{
Popular education with children. Dialogues between the pedagogy of the oppressed and the pedagogy of tenderness
}

\begin{abstract}
Starting from a brief analysis of the capitalist state as a social relationship and conceptualizing children as a minority in a situation of oppression, we begin the article by asking about the form of capitalist socialization that is condensed in the state institutionality and lodge the production and Reproduction of intergenerational binds marked by a specific form of violence: adultism. Subsequently, we analyze Freire's notions of oppression and banking education from a critical perspectives of adultism, and then we ask ourselves how to develop emancipatory pedagogies centered on dialogue if in our societies, children are not considered valid interlocutors. In an attempt to answer this question, we propose a combination of the pedagogy of the oppressed and the pedagogy of tenderness. From there, we invite you to take on the challenges of the political formation and organization of the new generations, promoting their prominence, and seeking to reinvent the pedagogies that contribute to the construction of emancipatory projects from a child, organized and class solidarity. We intend with this article to make a contribution to the theory and to the pedagogical practice from the specificity of popular education with children.
\end{abstract}

Keywords: popular education; childhood; adultcentrism; participation; tenderness.

\section{Introducción ${ }^{1}$}

Como es sabido, la aparición del pensamiento de Paulo Freire a finales de la década de 1960 dio empuje a la construcción de una corriente pedagógica liberadora, desde Latinoamérica, que pasaría al poco tiempo a ser conocida como "Educación Popular". Así, durante las siguientes décadas y al calor de luchas revolucionarias, se fue consolidando la apuesta político-pedagógica de la educación popular. Una educación rebelde, contestataria, que confía en las potencialidades de la condición humana, que valora los saberes de lxs educandxs, ${ }^{2}$ que lee el mundo desde la óptica de lxs de abajo. Una educación que afirma que enseñar no es transferir conocimientos sino crear condiciones para su producción colectiva. Una educación ligada orgánicamente al movimiento popular para fortalecer sus dinámicas organizativas y orientar las acciones prácticas en una perspectiva de clase. Una educación crítica y autocrítica. Una educación liberadora.

En un texto fundacional, Carlos Núñez plantea que la educación popular

(...) no solo debe entenderse como "concientizar" o desarrollar "conciencia crítica", sino darle a este hecho el sentido de la "conciencia solidaria", y esta en términos de "solidaridad de clase" que se vuelve práctica transformadora en la medida en que se convierte en solidaridad organizada de clase. (1996: 57)

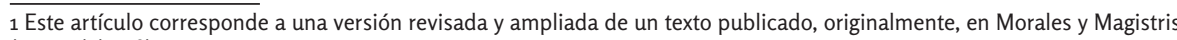
(comps.) (2018).

2 En esta publicación usaremos la equis ("x") como forma de nombrar todos los géneros: varones, mujeres y todas aquellas identidades que no formen parte del esquema binario hegemónico. El lenguaje no es transparente, nunca fue neutro y ha escondido durante siglos diversos modos de exclusión directa a determinadas poblaciones, invisibilizando las diferencias existentes bajo pretensiones de universalidad.
} 
Partiendo de que no es lo mismo desarrollar una educación popular con adultxs que con niñxs, ${ }^{3}$ nos preguntamos ¿en qué elementos radicarían las diferencias? ¿Qué tiene de distinto y/o específico una educación popular con niñxs? ¿En qué medida es posible una educación popular con niñxs que desarrolle una conciencia crítica que se convierta en "solidaridad organizada de clase"? ¿Qué obstáculos sociales, políticos y epistemológicos de carácter estructural tenemos que sortear para reconocer a niñxs como sujetxs políticxs? ¿Niñez, política y organización popular son nociones comulgables?

En este artículo pretendemos compartir unos planteamientos inacabados que surgen de la articulación entre el análisis teórico y la reflexión sobre nuestras experiencias concretas como educadores populares con niñxs. Ambos autores reflexionamos anclados en las experiencias pedagógico-políticas con niñxs de sectores populares que fueron impulsadas desde La Miguelito Pepe, ${ }^{4}$ de las que directa e indirectamente fuimos parte. Creemos necesario multiplicar las producciones teóricas que, articulando saberes provenientes de experiencias concretas, busquen sistematizar y recrear la especificidad de la educación popular con niñxs.

\section{Estado, socialización capitalista y adultismo}

Comenzaremos el presente ensayo dando cuenta de por qué creemos que el abordaje relacional del Estado (es decir, el Estado como relación social) se vuelve una llave privilegiada para analizar la forma de socialización capitalista, que afecta de modo decisivo a las nuevas generaciones.

Desde una óptica marxista, el Estado es causa, reflejo y consecuencia del tipo de sociedad en que vivimos, organizada en base a la existencia de dos clases contrapuestas: la burguesía y el proletariado. Entender al Estado como relación social (O’Donnell, 1978; Holloway, 1980; Hirsch, 2005; García Linera, 2015) supone un alejamiento de ciertos análisis marxistas que interpretan al Estado como mero aparato de represión de una clase contra otra. Siguiendo a Poulantzas, el Estado en la sociedad capitalista no es ni el instrumento de la clase dominante creado conscientemente, ni la encarnación de una "voluntad popular" democrática, ni un sujeto que actúa con autonomía; es más bien una relación social entre individuos, grupos y clases, "la condensación material de relaciones de fuerzas entre clases y fracciones de clases" (Poulantzas, 2005: 154). Estas relaciones sociales condensadas materialmente en el Estado son relaciones de dominación que, a través del modo de socialización capitalista, producen subjetividades en las nuevas generaciones que contribuyen significativamente a la reproducción del orden establecido (aunque no de manera totalizante, por lo cual la subversión intersticial se nos sigue presentando como desafío). El Estado, entonces, asume la materialización del proceso de estabilización de las relaciones sociales existentes en los cuerpos y marcos de percepción y de organización práctica y del mundo de cada persona. En este sentido, el Estado capitalista es la concretización de la constante formación de las estructuras mentales mediante las que las personas entienden el mundo existente y con las cuales

3 Tomando la definición de niñez de la Convención de los Derechos del Niño de 1989, a lo largo de todo el ensayo entenderemos por niñxs a las personas menores de dieciocho años.

4 La Miguelito Pepe es una organización de educadorxs populares que impulsa proyectos político-pedagógicos en diferentes barrios populares de Capital y Provincia de Buenos Aires, desde 2013. En cada barrio desarrolla diferentes tipos de talleres y espacios pedagógicos a cargo de educadorxs militantes. Fundamentalmente, promueve en todos los barrios espacios asamblearios donde los chicxs debaten y toman decisiones sobre lo que les resulta de interés; y espacios de encuentro y reflexión-acción para chicxs, donde problematizan el patriarcado y las violencias machistas. Se autodefinen como organización de educadorxs, en el sentido de que promueven - en tanto instancias apartadas-la autoorganización de niñxs. Así, la niñez organizada vinculada a La Miguelito Pepe no forma parte orgánica de dicho colectivo, sino que ha creado sus propias instancias organizativas: la Asamblea R.E.V.E.L.D.E., la Asamblea Pampa Rebelde y Rebeldes de Carcova, organizaciones de chicxs de 7 a 17 años de edad, cada una de las cuales cuenta con representantes niñxs. 
actúan ante ese mundo percibido (García Linera, 2015: 47); para esto es decisivo el modo en que se consuma el proceso de socialización de las nuevas generaciones.

El modo capitalista de relacionarnos (basado en la contradicción capital-trabajo) ha asumido como propias, e hizo necesarias para la reproducción de sus condiciones de producción, otras relaciones de dominio que lo exceden: nos referimos centralmente a las que caracterizan al patriarcado y al colonialismo. Estas relaciones de dominación, que existen desde antes del capitalismo, encuentran en él fértiles posibilidades para reproducirse, lo mismo que le sucede al capitalismo en ellas. En este sentido, Valdés Gutiérrez (2009) define al capitalismo como un sistema de dominación múltiple, es decir, no solo existe la relación de dominación que ejerce el capital frente al trabajo, sino que coexiste con otros sistemas de opresión: el colonialismo y el patriarcado, y también - agregamos nosotrxs - con el adultocentrismo (Alfageme, Martínez y Campos, 2003; Cussiánovich, 2010; Duarte Quapper, 2015).

El Estado capitalista, al organizar y asumir la materialización del proceso de socialización capitalista, no solo reproduce y mantiene las lógicas en las cuales se ampara la contradicción capital-trabajo, sino también toda la trama de relaciones de este sistema de dominación múltiple. Por lo tanto, no son únicamente las clases sociales en su vinculación contradictoria las que dan como resultado el modo de vida capitalista, ni tampoco son el mero resultado de un modo de socialización (el capitalista). Las clases sociales son la condición de posibilidad del modo de socialización capitalista a la vez que son producidas y reproducidas por el mismo modo de socialización que produce y reproduce - también - el colonialismo, el patriarcado y el adultocentrismo. El modo de socialización capitalista es el proceso que "acuña las estructuras e instituciones sociales en las cuales se expresan y entrelazan todos estos otros antagonismos sociales" (Hirsch, 2005: 171).

Cuando hablamos de adultocentrismo nos referimos a la estructura sociopolítica y económica de acuerdo con la cual el control integral lo ejercen lxs adultxs. Este posee carácter histórico-ancestral, de hecho los modos de producción previos al capitalismo también se valieron del adultocentrismo para su desarrollo y consolidación (Duarte Quapper, 2015: 413-414). Se trata de una categoría que nombra la relación asimétrica y tensional de poder que existe entre generaciones y al interior de las mismas. Duarte Quapper define al adultocentrismo

(...) como un sistema de dominación que delimita accesos y clausuras a ciertos bienes, a partir de una concepción de tareas de desarrollo que a cada clase de edad le corresponderían, según la definición de sus posiciones en la estructura social, lo que incide en la calidad de sus despliegues como sujetos y sujetas. (2015: 91)

Por otra parte, Alexanthropos Alexgaias, quien con diecisiete años escribió El Manifiesto Antiadultista, ofrece otra definición, agregando la diferencia entre adultocentrismo y adultismo:

\footnotetext{
El adultismo es un tipo de discriminación por edad (...), se define como la discriminación llevada a cabo por Ixs adultxs contra Ixs jóvenes. El adultocentrismo es el sistema en el que se encuadra la lógica del adultismo. Es decir, es la construcción jerárquica mediante la cual, lxs adultxs (...) son el centro de la sociedad, la cual está construida en base a sus términos, ideas, prejuicios y tópicos. (Alexgaias, 2014: 7)
}

El capitalismo se sirve del adultocentrismo para su propio desarrollo, ya que el hecho de que la adultez sea el modelo a seguir de modo acrítico provoca que las nuevas generaciones asimilen la ideología liberal como producto de su socialización (Duarte Quapper, 2015: 198). 
Como el Estado capitalista es una relación social que atraviesa a toda la sociedad y a todos sus componentes (las diferencias de clase, de género, de generación y etnia, además de las identidades colectivas, sus ideas, su historia y sus esperanzas), el socialismo, entendido como la transformación estructural de las relaciones de fuerzas entre los diferentes grupos subalternos con sus opresores y la creación de nuevas institucionalidades emancipatorias, necesariamente tendrá que atravesar al propio Estado, que por otra parte no es más que la concretización material e ideal, económica y cultural de esa correlación de fuerzas sociales (García Linera, 2015: 62).

\section{Opresión y educación bancaria desde perspectivas críticas del adultismo}

A partir de la preocupación por la educación del campesinado adulto analfabeto nació en Freire la reflexión sobre las condiciones y características del fenómeno de la opresión. Siguiendo a Lidia Rodríguez et al. (2007), su propuesta y pensamiento pedagógico no pueden comprenderse por fuera del contexto político intelectual de la década de 1960, y debe ser situado en uno de los lugares más pobres de América Latina: el Nordeste brasilero. Desde allí, fue Freire quien "por primera vez reconoce la especificidad del problema del aprendizaje de la alfabetización para sujetos adultos" (Rodríguez et al., 2007: 133). Así, anclado en esas preocupaciones y desafíos, el destinatario de la praxis pedagógica durante los años de desarrollo del pensamiento fundacional freireano y de la educación popular, fue el sujeto adulto. Como señala Puiggrós (1993) desde fines de la década de 1980 comenzó a producirse un desplazamiento de gran parte de las experiencias de educación popular, desde el campo revolucionario tradicional hacia un nuevo campo problemático: el de los derechos humanos. Es allí donde las problemáticas de las mujeres, de los indígenas, de lxs niñxs, de lxs refugiadxs, de grupos barriales y municipales, de sectores generacionales y otros, despuntaron como síntomas de un proceso de constitución de nuevos sujetos políticos. Sin embargo, la emergencia de esas problemáticas no implicó necesariamente que la teoría elaborada desde la educación popular fuera releída a la luz de las especificidades de lxs sujetxs en cuestión.

\section{¿Una pedagogía de lxs niñxs oprimidxs?}

En los últimos años de su vida y producción de teoría pedagógica, Freire dedicó obras completas a pensar la educación liberadora en las escuelas desde el rol docente, a analizar cuáles eran las premisas de las que había que partir para poder enseñar, cómo educar para la libertad, cómo confiar en y "querer bien" a lxs educandxs (2008a), como puede leerse en sus más destacadas obras en este sentido: Pedagogía de la autonomía (2008a) y Cartas a quien pretende enseñar (2009). Sin embargo, nos parece prudente afirmar que su vasto estudio sobre las formas de la opresión y su consecuente lucha desde la acción pedagógica como acción política de liberación han tenido como sujetos de su praxis —en tanto "unión inquebrantable entre acción y reflexión" (Freire, 1971: 103) - a lxs adultxs. Durante muchos años, como afirma Eliud Torres (2014), desde la educación popular no se pensó ni conceptual ni metodológicamente a la infancia porque dentro de las ciencias sociales lxs niñxs no figuraban como actores sociales. $\mathrm{Si}$ algo vino a visibilizar la nueva sociología de la infancia y los diferentes estudios sobre la niñez como fenómeno social es justamente eso: la necesidad de dejar de pensarlxs como hijxs, alumnxs o cuerpos en desarrollo, para pensarlxs como sujetxs sociales y políticxs (Qvortrup, 1993; Pavez Soto, 2012).

Cabe aclarar que no decimos esto para acusar la falta, sino para reflexionar en torno a los desafíos que tenemos por delante. En aquellos años, el estudio de la infancia formaba parte de las investigaciones sobre la familia y/o la escuela, ocupándose de 
lxs niñxs de un modo instrumental (Pavez Soto, 2012: 83). Su análisis solo resultaba importante considerando a la infancia como una etapa determinante para la constitución del ser adultx.

En función de la relación desigual de poder con el mundo adulto que estructura las formas de ser, pensar y sentir de lxs niñxs, estxs han introyectado la conciencia adultista. Tal como lo entiende Freire, por la dialéctica propia del vínculo contradictorio opresorxs/oprimidxs, quienes se encuentran en desventaja en esa relación introyectan la conciencia de lxs opresorxs, hacen propia la cosmovisión de su antagónicx, renegando y denigrando lo propio de su clase. Tal es así que "Ser" significa ser como lxs opresorxs. No casualmente la matriz de pensamiento adultista considera a lxs niñxs como seres "aún-no" y a lxs adultxs como seres "ya-sî" (Liebel, 2006).

En este sentido, nos parece importante empezar a nombrar y reconocer prácticas que alojan en sí una carga de opresión. Negar la palabra es una forma de opresión. Golpear como si no se sintiera dolor, también. Prohibir realizar determinadas acciones o actividades económicas, sociales, culturales, deportivas, bajo el pretexto de que perjudican a lxs niñxs sin hacerlxs parte de esa definición, es opresión. ${ }^{5}$ Obligar a ser de cierta manera, o imponer la carrera/estudio/profesión también es opresión. Subestimar la capacidad de resolver situaciones, ningunear como sujetx de pensamiento, y tantas otras prácticas cotidianas del mundo adulto hacia el mundo de la niñez, son opresivas.

A diferencia de lo que sucedía en las ciencias sociales durante las décadas de 1960, 1970 y 1980, hoy entendemos a la niñez como categoría social permanente, parte insustituible de la estructura de cualquier sociedad (Qvortrup, 1993). Desde aquí nos atrevemos a aventurar que es preciso construir colectivamente una pedagogía de lxs niñxs oprimidxs, para que asumiéndose (y asumiéndolxs, lxs adultxs) sujetxs sociales en situación de opresión, alcemos desde ellxs una pedagogía de y para su emancipación. ${ }^{6}$

\section{Educación bancaria y adultismo}

El pensamiento freireano postula a la educación bancaria como perpetuadora de la relación de opresión entre lxs dominadxs y lxs dominadorxs. Denomina a la educación tradicional como "bancaria" porque concibe a lxs educandxs como bancos en los que hay que depositar saber, "valores educativos". Este tipo de educación se caracteriza por reproducir la contradicción opresorxs/oprimidxs al interior del ámbito escolar, la cual toma la forma de la contradicción educadorxs/educandxs. Lxs educadorxs son lxs sujetxs del proceso educativo y lxs educandxs meros objetos. Son lxs educadorxs, únicamente, quienes educan, saben, piensan, hablan, disciplinan, optan y prescriben su opción, actúan, escogen el contenido programático. Por el contrario, lxs educandxs son -exclusivamente- educadxs, no saben, son objetos pensados, escuchan dócilmente, son destinatarios del disciplinamiento, siguen acríticamente la prescripción de lxs educadorxs, no escogen el contenido programático (Freire, 1971). Que la educación bancaria reúna estas características tiene sentido, ya que "sería en verdad una actitud

5 Como señala la investigadora inglesa Lansdown, "es el predominio de un modelo proteccionista en la construcción de nuestras relaciones con los niños lo que, muchas veces, ha impedido que se desarrolle un reconocimiento adecuado de la capacidad de participación real de ellos. (...) Y es su necesidad de protección de la que los adultos se han valido para justificar su persistente resistencia a conceder a los niños el derecho de tomar decisiones propias en su vida. Es así cómo se establece un círculo afirmador. Pues, atribuyendo a los niños una falta de competencia para decidir su vida, se los considera vulnerables y necesitados de protección. Y porque necesitan protección, los adultos se creen apoderados para actuar en su lugar. Negando a los niños el poder de tomar decisiones o de participar en ellas de manera amplia, su vulnerabilidad ante la autoridad adulta crece aún más" (Lansdown, 1995: 22).

6 Afirmar esto, y problematizar el carácter opresivo del vínculo intergeneracional no implica postular un desdibujamiento ni del rol adulto ni de sus responsabilidades indelegables vinculadas al cuidado de las nuevas generaciones. No se trata de impugnar el adultocentrismo proponiendo una niñocracia, sino de problematizar las instancias en las que la afirmación de lo adulto significa —en términos dialécticos— la negación de lo niño. 
ingenua esperar que las clases dominantes desarrollen una forma de educación que permitiese a las clases dominadas percibir las injusticias sociales de forma crítica" (Freire, 1985: 71).

Desde los marxismos - en general y en plural-, la educación escolar se identifica como un elemento fundamental para la reproducción del orden social capitalista (Althusser, 1968; Baudelot y Establet, 1976; Bourdieu y Passeron, 1977): de su ideología burguesa, fatalista, patriarcal, colonial; de su disciplinamiento de los cuerpos, de los deseos, de las sexualidades posibles; de su concepción fragmentada del conocimiento, su "objetividad" y "apoliticidad". Ahora bien, el planteo freireano no indica, como se creyó durante un tiempo, que la escuela es solamente reproducción, opresión y domesticación. Basta mirar las trayectorias de tantísimxs chicxs de sectores populares que, gracias a su paso por la escuela y por haberse cruzado con ciertx maestrx, pudieron torcer el rumbo al que les conducía su lugar en la estructura social.

Y, en este sentido, no es lo mismo hablar de la escuela pública que de la escuela privada. Más allá de sus contradicciones y determinaciones, la escuela pública es un espacio de resistencia y de disputa para la construcción de nuevas subjetividades. Es el principal ámbito público que recibe, contiene y alimenta a lxs niñxs en contextos de vulnerabilidad. La escuela pública debe ser defendida por educadorxs, trabajadorxs docentes y no docentes, estudiantes, sus familias y la comunidad toda. Es una institución estatal en la cual muchxs educadorxs sostienen heroicas contiendas: contra los intentos por vaciarla de presupuesto y legitimidad social; contra las propias trampas que estructuran el sistema educativo y obstaculizan la construcción colectiva, los procesos comunitarios participativos, el desarrollo de una educación problematizadora; contra los aparentes destinos que condenarían a lxs niñxs de sectores populares a padecer violencias e injusticias ad eternum, invitándolxs a soñar y luchar por utopías.

Con Freire, y desde su pensamiento no determinista sino dialéctico, consideramos que la organización sindical de docentes combativxs y críticxs es un ámbito fértil para la lucha política en una perspectiva estructuralmente transformadora. Si bien Freire critica la educación bancaria, ello no implica su rechazo a las potencialidades políticas y pedagógicas de la labor educativa en el sistema formal de educación, ya que "la nueva educación (...) no se crea en su totalidad de inmediato después de la llegada de la revolución al poder. Comienza, en algunas de sus dimensiones, mucho antes: en la movilización y en la organización populares para la lucha" (Freire y Faundez, 2013: 133).

Sin embargo, las limitaciones que allí se presentan son profundas. Es que la institución escuela condensa el conjunto de relaciones sociales contradictorias que el modo de socialización capitalista produce y reproduce. Es una pieza clave de la forma capitalista de socialización. En ella, el Estado concretiza la formación constante de las estructuras mentales con las que las personas entendemos el mundo existente y con las cuales actuamos en y ante el mundo percibido (García Linera, 2015: 47). Así, a los fines de este trabajo, resulta central afirmar que la institucionalidad escolar (en tanto parte de la institucionalidad estatal) es un ámbito en el que se imponen relaciones sociales intergeneracionales basadas en la violencia adultista.

En la escuela la violencia adultista se expresa en múltiples aspectos. En el ejercicio desigual del poder, en la negación de lxs niñxs como interlocutorxs válidxs, en la subestimación de sus capacidades para asumir responsabilidades y tomar decisiones, en su negación como sujetxs políticxs, de acción transformadora. En otras palabras, la escuela - así como la familia burguesa y demás instituciones sociales, cada una bajo su especificidad - produce, naturaliza y reproduce un modo de vínculo intergeneracional fundado en una violencia de tipo adultista, propio de una sociedad adultocéntrica. 


\section{La ternura como condición del diálogo intergeneracional emancipatorio}

No hay pedagogía emancipatoria que no tenga como base el diálogo, pues significa encuentro entre seres humanos y es "condición fundamental para su verdadera humanización" (Freire, 1971: 178). El diálogo nace de una matriz crítica y genera criticidad, se nutre del amor, de la humildad, de la esperanza, de la confianza entre las personas. El diálogo es una relación horizontal de A con B. Solo un diálogo basado en estas características produce comunicación. Sin alguno de estos elementos, no hay comunicación ni diálogo: hay un mero intercambio de ideas, un monólogo entre dos.

Entonces, si no hay educación popular sin diálogo: ¿cómo dialogar con lxs niñxs si el carácter adultocéntrico de la sociedad nos impone la certeza de que no son interlocutorxs válidxs?

Lxs adultxs nos relacionamos con las nuevas generaciones creyéndonos sujetxs únicxs de pensamiento, y por lo tanto imponiendo nuestros criterios sobre el mundo como "lo válido", "lo racional", "lo justo", "lo verdadero". Aquí es relevante considerar a Boaventura de Sousa Santos (2009) cuando plantea la noción de "injusticia cognitiva" en tanto aquella idea que considera como únicamente válido el conocimiento proveniente de la ciencia moderna, obviamente desarrollada por adultxs, lo cual niega cualquier tipo de conocimientos-otros. Esto se vuelve un obstáculo muy grande para que haya diálogo. Pero lo que lo hace aún más complejo, es que -como ya señalamos más arriba- lxs mismxs niñxs no se consideran interlocutorxs válidxs, es decir, muchas veces no comunican sus opiniones porque "dirán una tontería"; no comparten sus ideas porque no se consideran capaces de decir algo que para el adulto no sea "obvio". Las nuevas generaciones, producto de la forma capitalista de socialización, incorporan como natural la ideología del opresor.

En este sentido, la violencia adultista no solo es ejercida por lxs adultxs, es producida, naturalizada y reproducida por lxs mismxs niñxs.

¿Cómo dialogar, entonces, con lxs niñxs? En primer lugar, para que haya diálogo "es necesario que existan condiciones de reconocimiento" (Korol, 2017: 22), es decir, es necesario reconocer que lxs niñxs, más allá de su edad cronológica, son interlocutorxs válidxs, y que somos lxs adultxs lxs que, muchas veces, no sabemos comprender sus modos de comunicarse. En este sentido es que se vuelve una exigencia saber escuchar, para poder enseñar (Freire, 2008a: 107). Porque escuchar, no meramente oír, implica valorar la palabra del otrx y, en ese mismo acto, reconocer la otredad.

En segundo lugar, para que haya diálogo es fundamental cuestionar los privilegios adultos y disponerse a la construcción de nuevos modos de ser adultx. Adultxs que sin perder el lugar de educadorxs, entiendan que también son compañerxs de lxs niñxs. Adultxs que entiendan que no saben más sino que saben distinto, que acepten que no siempre tienen la razón y que también se equivocan, que sepan admitir que tienen contradicciones y las reconozcan cuando se las señalan. Adultxs que en la relación con niñxs demuestren que tratan con sujetos (no con objetos receptores de comunicados emitidos desde "arriba"), es decir, personas con deseos, aspiraciones, gustos y miedos, de quienes mucho pueden aprender, con quienes tendrán que acordar aquellas decisiones que los afecte a ambxs, sin perder la dimensión de cuidado, y sin significar esto que tiene que hacerse "todo lo que quieran lxs niñxs". Se trata de una radical apuesta por socializar el poder, asumiendo que el mejor modo de proteger a lxs niñxs es invitándolxs a participar integralmente en su desarrollo y en la vida social y política del tiempo histórico que habitan (Liebel, 2006). Este tipo de adultez — nueva - tenemos que crearla colectivamente, los adultxs junto a las nuevas generaciones en diálogo confraternal. 
En tercer lugar, así como sin diálogo no hay educación liberadora, sin ternura no hay diálogo intergeneracional posible. No nos referimos a la ternura como trato dulce, suave, delicado. Con Cussiánovich, entendemos la ternura como experiencia vivencial (2015: 227), es decir, como aquello que emerge de un encuentro entre afectos, singularidades que se desean, sujetos vinculados mediante un lazo afectivo, un lazo de amor. En Freire el amor también es fundamento del diálogo: "si no amo el mundo, si no amo la vida, si no amo a los hombres, no me es posible el diálogo" (1971: 107). Pero el amor al que se refiere Freire es un amor a la humanidad en tanto esencia del ser revolucionario: se trata de un amor genérico, a la condición humana.

En el caso de las pedagogías emancipatorias con niñxs oprimidxs por la desigualdad de clase, de generación, de género y etnia, esta concepción del amor como fundamento del diálogo es necesaria, pero insuficiente. Ese amor necesita fundirse en un lazo social afectivo. El diálogo intergeneracional emancipatorio puede existir si está cimentado en una relación afectiva entre educadorxs y educandxs, en un vínculo humano sincero, ya que - como afirmara Cussiánovich - "solo se aprende para la vida lo que viene acompañado de cariño, de lazo afectivo, de saberse valorado, de tener la experiencia de ser queridos tal y como uno es" (2010:33).

Estamos llamados, como educadorxs de niñxs marcadxs por la injusticia, a "saber ser" a fin de facilitar la construcción de vínculos significativos que "seduzcan a la vida" (Morlachetti, 2007: 269) y que generen experiencias de encuentro. Para hacerlo, tal como expresara Lorenzo Milani, "la preocupación esencial no tiene que ser cómo debe enseñarse, sino cómo debe ser uno para poder enseñar" (citado en Palacios, 2010). Humildad, búsqueda permanente de coherencia, generosidad, seguridad y sabiduría afectiva, integridad ética, confianza en las potencialidades de lxs educandxs, escucha, curiosidad, valoración del otrx y de su dignidad, asunción de la inherente politicidad del acto educativo, y la convicción de que muchas veces en materia educativa - como expresara el poeta cubano José Martí- "la mejor manera de decir, es hacer" (citado en Turner Martí, 2007: 58). Con estas cualidades no pretendemos postular la necesidad de educadores-superhéroes y educadoras-superheroínas, sino un horizonte que nos guíe en nuestras búsquedas.

Decimos esto porque la construcción de los lazos afectivos no se da por añadidura. En este sentido, no se trata simplemente de ir a "dar ternura" a un grupo de niñxs. La ternura no se reparte, no se derrama de unxs a otrxs. La ternura emerge en un encuentro pedagógico (Cussiánovich, 2015: 236). Y que haya encuentro significa sentirse parte de un grupo, en el cual se cree tener algo para dar, pues se confirma que lxs otrxs lo reciben con alegría. Significa sentirse bien, contenidx y reconocidx, sabiendo que "el reconocimiento es expresión y concreción de aprecio, de afecto, de valoración, es el embrión de la solidaridad" (Cussiánovich, 2010: 109). Significa que no dé lo mismo si alguien no está, porque le pudo haber pasado algo, o haberse sentido mal la reunión anterior. Significa lazo afectivo e identidad colectiva. Significa deseo de ser y estar ahí, con esxs otrxs que se vuelven nosotrxs.

En resumen, desde esta perspectiva se vuelve un desafío pretendernos educadorxs antiadultistas. Así, creemos que se verá facilitado el encuentro pedagógico, podrá emerger la ternura y se volverá posible el diálogo intergeneracional como corazón de una pedagogía emancipatoria con niñxs.

\section{Protagonismo político y social de la niñez: los retos de promover la formación política y la organización}

El horizonte anticapitalista no será emancipatorio si no se asume también antiadultocéntrico; del mismo modo que este no será emancipatorio si no se asume además 
anticapitalista. Como ya se señaló, la sociedad capitalista funciona como sistema de dominación múltiple, esto implica que dicho modo de organización económico-político está unido a una civilización culturalmente excluyente, patriarcal, discriminatoria, depredadora y productora de violencia (Valdés Gutiérrez, 2009). Por tanto, la lucha por una transformación social estructural deberá asumirse antiadultocéntrica, anticapitalista, feminista, decolonial y en rebeldía contra cualquier forma de opresión.

Una de las conquistas histórico-políticas más significativas de los diferentes "movimientos infantiles" (Liebel, 2000) que surgieron en América Latina a fines de la década de 1970 y durante la década de 1980 es haber puesto en práctica ya desde ahora - como diría Gramsci (Ouviña, 2016: 142) - un paradigma de infancia de carácter emancipatorio: el paradigma del protagonismo de la niñez (Liebel, 2000; Alfageme, Martínez y Cantos, 2003; Cussiánovich, 2010).

El protagonismo de la niñez como horizonte comenzó a postularse en América Latina, entonces, hace ya casi cuarenta años junto con el nacimiento y desarrollo de diversas experiencias de organización social y política de niñxs. Sin desconocer la pluralidad de experiencias que aportaron a tal arribo, vale decir que los movimientos sociales de NATs (niñxs y adolescentes trabajadorxs) se volvieron expresión por antonomasia de la elaboración y exigencia de dicho paradigma y, por lo tanto, de la necesidad de avanzar todavía mucho camino en la perspectiva de fortalecer el protagonismo social de las nuevas generaciones.

El mismo, en tanto respuesta a la negación del sujeto niñx, en tanto propuesta relacional emancipatoria, y en tanto apuesta por construir una nueva sociabilidad humana, no podrá ser conquistado cabalmente sin — aunque parezca una obviedad - la participación política protagónica de las nuevas generaciones. Este paradigma nos interpela a cuestionar el adultocentrismo, elevando y/o consolidando el estatus político y social de lxs niñxs en nuestras sociedades al pretender generar una ruptura con cualquier forma de violencia adultista.

Para ello se vuelve menester abordar cuestiones políticas desde la perspectiva de niñxs. Esto implica pensar la noción de política a la luz de lo niño, además de examinar la relación que hay entre ambas, con y sin mediación de lxs adultxs, pues si bien es cierto que es crucial el acompañamiento de lxs adultxs en el paulatino acercamiento a la acción política, resulta fundamental conocer cómo los niñxs desarrollan, adquieren y significan por sí mismos (en las experiencias políticas que viven) saberes y prácticas políticas (Torres, 2012).

Debido a la relación desigual de poder entre adultxs y nuevas generaciones, ambos actores parten del supuesto de que, en términos de iniciativa política (en sentido amplio), lo que tienen para hacer o decir lxs más grandes es "mejor", "más inteligente", "más importante", "más valioso", etc. Así, por más que lxs niñxs tengan alguna idea o impulso, es habitual la autocensura porque se saben en permanente estado de evaluación, porque piensan que lo que tienen para proponer será desatinado, y/o porque muchas veces lxs adultxs reafirmamos nuestra autoridad señalando errores de modo coercitivo, subrayando las faltas, y por ende impugnando las iniciativas. Por esto, reconocer a lxs niñxs como sujetxs políticxs implica, en efecto, promover la pluralización del espacio público, impulsando que este logre adaptarse a lxs niñxs en formas apropiadas y no solamente que estxs se adapten a formas premoldeadas por adultxs en las que no tuvieron ninguna participación. Y en términos pedagógicos, para tales propósitos - como venimos planteando- es decisivo que existan interacciones sociales marcadas por el afecto, por el amor humano (Cussiánovich, 2010). Pero con eso no basta. Afirmar que "no podemos hablar de protagonismo sin reconocer que es en la pedagogía de la ternura que encuentra su condición" (Cussiánovich, 2010: 165), implica entender esa 
afectividad como fundiéndose en un vínculo que potencia, que cree en lxs otrxs, que lxs persuade a ser más, que lxs invita a desafiar y desafiarse, que facilita experiencias protagónicas, que lxs seduce para la transformación del mundo. Pero no para que esxs sujetxs hagan, sean y sientan lo que lxs adultxs educadorxs consideran apropiado, necesario y valioso; sino para que esxs sujetxs descubran sus propias ideas, construyan sus convicciones, protagonicen sus propios procesos de desafíos colectivos y, equivocándose, vayan trazando el sendero de su ser auténticxs, rebeldes.

Como plantean Alfageme, Martínez y Cantos (2003), el protagonismo de la niñez posee de manera inherente un carácter político, social, cultural, ético y espiritual que exige una pedagogía y nos invita a replantear el estatus social de la niñez y la adultez en la sociedad. Estamos llamadxs, entonces, a construir con lxs niñxs una educación popular que promueva y viabilice procesos y experiencias colectivas para que las nuevas generaciones ejerzan plenamente su condición de sujetxs políticxs a fin de que puedan ser lxs protagonistas del proceso de lucha por su propia emancipación.

\section{Formación política y organización de la niñez popular}

Una subjetividad otra, nueva, politizada, emancipatoria no surge espontáneamente. El modo de socialización capitalista influye de forma decisiva en la construcción de la subjetividad de las nuevas generaciones. Del mismo modo que - como escribiera Lenin - "el desarrollo espontáneo del movimiento obrero marcha precisamente hacia su subordinación a la ideología burguesa" (1961: 150), "renunciar a formar al niño escribe, ahora, Gramsci- significa tan solo permitir que su personalidad se desarrolle recogiendo caóticamente del ambiente general todos los motivos de su vida" (2009: 247). Con otras palabras, Aníbal Ponce plantea algo similar, pues para él "respetar la 'libertad del niño' dentro de la sociedad burguesa equivale ni más ni menos que a decir: renuncio a oponer la más mínima resistencia a las influencias sociales formidables y difusas con que la burguesía los impregna en su provecho" (1970: 190).

Para que lxs niñxs ejerzan con plenitud su condición de sujetxs políticxs se vuelve necesario asumir el reto de la formación política de las nuevas generaciones, entre otros. Formación antiadultista, ubicando a lxs mismxs niñxs como sujetxs del proceso y jerarquizando las experiencias (acciones y vivencias concretas) como insumo privilegiado desde el cual iniciar el proceso de problematización y aprendizaje. Es una invitación a abordar la compleja tensión entre dejar lugar al surgimiento de ideas, sentires e iniciativas propias de lxs niñxs y acercarles matrices de análisis de la realidad y de acción en ella que sean críticas a los estímulos que nuestras sociedades nos/les ofrecen.

La formación política de las nuevas generaciones no puede basarse en el acto de depositar y transferir conocimientos. Así caeríamos en prácticas de adoctrinamiento. “Cómo se pretende enseñar el 'ABC de La Revolución' — se pregunta Korol— reproduciendo metodologías en las que hay abuso de 'bajada de línea, transmisión vertical y jerárquica de conocimientos considerados como 'verdades de hierro'?" (2017: 13). La educación liberadora debe generar, en tanto situación gnoseológica, un acto cognoscente. Es decir, el objeto cognoscible, en lugar de ser lo que depositan lxs educadorxs bancarixs en las conciencias ajenas, debe ser lo que mediatiza la relación entre sujetxs cognoscentes. Ese objeto cognoscente debe ser, en palabras de Freire, el mundo (1971: 112). En el caso de la educación con niñxs, lo que mediatiza el proceso educativo tampoco puede ser un conocimiento a ser depositado en ellxs y desvinculado de sus vidas, eso es lo que hace la educación bancaria tal como lo describe Celestine Freinet: "vosotros [lxs docentes bancarixs] decís: 'están en la luna' (...) Están en la realidad, en la realidad de su vida, y sois vosotros los que pasáis de largo con vuestro vacilante cabo de vela" (1973: 57). La educación tiene que ser sobre, en y desde la vida de lxs niñxs. De hecho, el mundo al que se refiere Freire es la vida misma de lxs niñxs. Y, a la vez, dicha pedagogía tiene 
que estar intrínsecamente vinculada a procesos de transformación de la realidad, a proyectos concretos en los cuales poner en acto los sueños y las alegrías, al tiempo que formas de abordar los miedos y las tristezas del colectivo de niñxs específico que se acompaña. Es entonces el mundo y las acciones colectivas para transformarlo el objeto cognoscente que ha de mediatizar una situación gnoseológica entre educadorxs y niñxs.

El reconocimiento de lxs niñxs como sujetxs en situación social de opresión nos invita a promover experiencias y procesos sociales y políticos donde lxs niñxs vayan siendo protagonistas en tanto actores sociales relevantes. Para ello, en tanto lxs opresorxs de lxs niñxs no pertenecen solamente a la clase dominante (pues sus opresorxs también somos lxs adultxs), se nos presenta como desafío favorecer la creación de organizaciones sociales y políticas de niñxs integradas, representadas y dirigidas por ellxs. Lxs niñxs, como señala Sandra Carli, no cuentan con "herramientas institucionales concretas para presentar sus demandas y exigir una respuesta de los gobernantes". Menos aún consiguen "asumir por sí mismos, en persona, su propia representación en el interior de las instancias legítimas de toma de decisiones" (Carli, 2009: 65). Creando sus propias herramientas reivindicativas las nuevas generaciones podrán asumir por sí mismas un conjunto de tareas indelegables y disputarle al Estado y a la sociedad todas aquellas reivindicaciones que les permitan avanzar en este proceso emancipatorio. Desde sus organizaciones, con el acompañamiento de educadorxs antiadultistas, tendrán el reto de combatir las distintas instancias e instituciones que generan violencias estructurales hacia ellxs.

Para tal fin, la tarea de lxs educadorxs populares es decisiva. No ingenuamente Ernani María Fiori escribió, en la introducción a la Pedagogía del oprimido, que

(,,) los dominadores mantienen el monopolio de la palabra con que masifican, mitifican y dominan. En esa situación, los dominados, para decir su palabra tienen que luchar para tomarla. Aprender a tomarla de los que la retienen y niegan a los demás, es un difícil, pero imprescindible aprendizaje: es la pedagogía del oprimido. (Fiori en Freire, 1971: 26)

Asumiendo las especificidades propias de una organización de niñxs, lxs mismxs protagonistas tendrán ante sí la responsabilidad de no reproducir las metodologías, lógicas de funcionamiento y modelos relacionales de muchas organizaciones y movimientos sociales y políticos que, bregando por una transformación radical de la sociedad, reproducen en su interior aquellas relaciones sociales de opresión contra las que luchan. Y, en este sentido, lxs educadorxs se enfrentan al desafío de estar alertas, a fin de no inculcar en lxs chicxs modelos adultistas, donde lxs militantes más valiosos sean aquellxs que con mayor claridad y bravura pueden repetir el discurso de lxs adultxs referentes.

\section{Conclusiones}

La teoría e historia de la educación popular es preponderantemente la teoría e historia de una pedagogía emancipatoria pensada y dirigida para el mundo adulto (Rodríguez, 2013). Creemos vital advertir sobre la necesidad de construir colectivamente, desde las experiencias concretas, una educación popular pensada y dirigida para lxs niñxs. Para ello, creemos que es decisivo asumir el carácter opresivo del vínculo intergeneracional y promover el protagonismo de la niñez, reconociendo que es en la pedagogía de la ternura donde encuentra su condición. A lo largo de América Latina y el Caribe vienen desarrollándose experiencias emancipatorias de educación popular con niñxs, pero pocas de ellas han podido ser sistematizadas. Consideramos muy importante que el pensamiento sobre educación popular con niñxs, producido desde experiencias 
concretas por educadorxs populares, pueda sistematizarse y elaborarse de tal forma que sea reconocido en los ámbitos que detentan el poder real y simbólico de la producción de conocimiento, tanto en la institucionalidad académica como en los movimientos sociales.

Desarrollar una "solidaridad organizada de clase" (Núñez, 1996) puede colocarse no solo como objetivo político-pedagógico de la educación popular de adultxs, sino también como desafío histórico desde la labor educativa con niñxs en proceso de subjetivación política emancipatoria, en lucha contra el adultocentrismo y por vidas sin violencia. Pero para condensar semejante objetivo en prácticas pedagógicas se vuelve necesario reconocer para visibilizar que no es lo mismo una educación popular con adultxs que una educación popular con niñxs. Con este artículo pretendemos invitarnos, inspirarnos, a seguir pensando cómo asumir los desafíos de la construcción de una educación popular con niñxs, promoviendo la formación y la organización política de las nuevas generaciones, su protagonismo, y deseando reinventar las pedagogías que acompañen la construcción de proyectos emancipatorios desde una solidaridad niña, organizada y de clase. 


\section{Q Bibliografía}

"Alexgaias, A. (2014). El Manifiesto Antiadultista. Galicia, Distribuidora Anarquista Polaris.

» Alfageme, E.; Martínez, M. y Cantos, R. (2003). De la participación al protagonismo infantil. Propuestas para la acción. Madrid, Edición Plataforma de Organizaciones de Infancia.

" Althusser, L. (1968). Ideología y Aparatos Ideológicos del Estado. En La filosofía como arma de la revolución, pp. 102-151. México, Siglo XXI.

» Baudelot, Ch. y Establet, R. (1976). La escuela capitalista en Francia. Madrid, Siglo XXI.

» Bourdieu, P. y Passeron, J. C. (1977). La reproducción. Barcelona, Laia.

»Carli, S. (comp.) (2009). La cuestión de la infancia. Entre la escuela, la calle y el shopping. Buenos Aires, Paidós.

"Cussiánovich, A. (2010). Aprender la condición humana. Ensayo sobre pedagogía de la ternura. Lima, Ifejant.

"Cussiánovich, A. (2010). Paradigma del protagonismo. INFANT, Serie Materiales de Trabajo $\mathrm{N}^{\circ}$ 2, Lima.

»Cussiánovich, A. (2015). Ensayos Il sobre Pedagogía de la Ternura. Aprender la condición humana. Lima, Ifejant.

»De Sousa Santos, Boaventura (2009). Una epistemología del sur: la reinvención del conocimiento y la emancipación social. México, Siglo XXI/CLACSO.

» Duarte Quapper, C. (2015). El adultocentrismo como paradigma y sistema de dominio. Análisis de la reproducción de imaginarios en la investigación social chilena sobre lo juvenil. Disponible en: http://www.tdx.cat/handle/10803/377434

»Freinet, C. (1973). Parábolas para una pedagogía popular. Barcelona, Laia.

》Freire, P. (1971). Pedagogía del oprimido. Montevideo, Tierra Nueva.

"Freire, P. (1985). La importancia de leer y el proceso de liberación. México, Siglo XXI.

"Freire, P. (2008a). Pedagogía de la autonomía. Saberes necesarios para la práctica educativa. Buenos Aires, Siglo XXI.

"Freire, P. (2008). Pedagogía de la esperanza. Un reencuentro con la pedagogía del oprimido. Buenos Aires, Siglo XXI.

» Freire, P. (2009). Cartas a quien pretende enseñar. Buenos Aires, Siglo XXI.

»Freire, P. y Faundez, A. (2013). Por una pedagogía de la pregunta. Crítica a una educación basada en respuestas a preguntas inexistentes. Buenos Aires, Siglo XXI.

» García Linera, A. (2015). Socialismo comunitario. Un horizonte de época. Buenos Aires, Luxemburg.

"Gramsci, A. (2009). Antología Antonio Gramsci. Selección de Manuel Sacristán. Buenos Aires, Siglo XXI.

"Hirsch, J. (2005). ¿Qué significa Estado? Reflexiones acerca del Estado capitalista. Revista de Sociología e Política, junio. Curitiba, Universidade Federal do Paraná.

» Holloway, J. (1980). El Estado y la lucha cotidiana. Cuadernos Políticos, no 24 7-27, 
abril-junio. México, D.F. Disponible en: http://www.cuadernospoliticos.unam.mx/ cuadernos/

» contenido/CP.24/CP24.3.JohnHolloway.pdf [consultado 26/10/2019]

》 Korol, C. (comp.) (2017). Diálogo de saberes y pedagogía feminista. Educación Popular. Buenos Aires, América Libre.

"Lansdown, G. (1995). Children's rights to participation: a critique. En Cloke, C. y Davies, M. (eds.). Participation and Empowerment in Child Protection. Chichester, John Wiley \& Sons Ltd.

»Lenin, V. I. (1961). Obras escogidas en tres tomos, Tomo I. Moscú, Progreso.

" Liebel, M. (2000). La Otra Infancia. Niñez trabajadora y acción social. Lima, Ifejant.

» Liebel, M. (2006). Entre protección y emancipación. Derechos de la infancia y políticas sociales. Monografías del experto en Políticas Sociales de Infancia, Serie Teoría $N^{\circ}$ 1. Madrid, Universidad Complutense.

"Morales, S. y Magistris, G. (comps.) (2018). Niñez en movimiento. Del adultocentrismo a la emancipación. Buenos Aires, Chirimbote/El Colectivo/Ternura Revelde.

" Morlachetti, A. (2007). Crónicas desangeladas. Buenos Aires, Fundación Pelota de Trapo.

"Núñez, C. (1996). Educar para transformar. Transformar para educar. Buenos Aires, Lumen Humanitas.

"O’Donnell, G. (1978). Apuntes para una teoría del Estado. Revista Mexicana de Sociología, Vol. 40, № 4, Estado y Clases Sociales en América Latina (2) oct.-dic.: 1157-1199.

》 Ouviña, H. (2016). La pedagogía prefigurativa en el joven Gramsci. Una aproximación a la teoría y práctica de la educación futura. En Hillert, F.; Suárez, D.; Rigal, L. y Ouviña, H. Gramsci y la educación: pedagogía de la praxis y políticas culturales en América Latina. Buenos Aires, Noveduc.

"Palacios, J. (2010). La cuestión escolar. Buenos Aires, Colihue.

"Pavez Soto, I. (2012). Sociología de la Infancia: las niñas y los niños como actores sociales. Revista de Sociología, № 27: 81-102. Facultad de Ciencias Sociales, Universidad de Chile.

"Ponce, A. (1970). Educación y lucha de clases. Buenos Aires, El viento en el mundo.

»Poulantzas, N. (2005). Estado, Poder y Socialismo. México, Siglo XXI.

»Puiggrós, A. (1993). Historia y prospectiva de la educación popular latinoamericana. En Educación popular. Crisis y perspectivas. Buenos Aires, Miño y Dávila.

"Qvortrup, J. (1993). Nine Theses about "Childhood as a Social Phenomenon". En Qvortrup, J. (ed.). Childhood as a Social Phenomenon. Lessons from an International Project. Viena, European Centre for Social Welfare Policy and Research.

"Rodríguez, L. M.; Marin, C.; Moreno, S. M. y Rubano, M. del C. (2007). Paulo Freire: una pedagogía desde América Latina. Ciencia, Docencia y Tecnología, XVIII(34). Disponible en: https://www.redalyc.org/pdf/145/14503404.pdf [Consulta 26/10/2019].

》 Rodríguez, L. M. (dir.) (2013). Educación popular en la historia reciente en Argentina y América Latina. Aportes para balance y prospectiva. Buenos Aires, APPEAL.

"Santos, B. de S. (2009). Una epistemología del sur: la reinvención del conocimiento y la emancipación social. México, Siglo XXI/CLACSO. 
"Torres, E. (2012). La participación de niños y niñas en pueblos indígenas que luchan por su autonomía. Rayuela, año 4, № 7, noviembre 2012/mayo 2013. México, Ednica IAP.

» Torres, E. (2014). Niños y niñas como sujetos políticos. La participación infantil en movimientos sociales. Memorias del IV Congreso Nacional de Ciencias Sociales, t. 11, Acción Colectiva y movimientos sociales. CMCS/UCyA de Chiapas/CESMyC, Tuxtla Gutiérrez, Chiapas/Tijuana, Baja California.

» Turner Martí, L. (2007). Del pensamiento pedagógico de Ernesto Che Guevara. La Habana, Capitán San Luis.

»Valdés Gutiérrez, G. (2009). América Latina: Posneoliberalismo y movimientos antisistémicos. La Habana, Editorial de Ciencias Sociales.

\section{Santiago Morales}

Sociólogo, Universidad de Buenos Aires. Maestrando en Educación Popular de Adultos, Universidad Nacional de Luján. Investigador del proyecto UBACyT "Estado, movimientos sociales y derecho a la educación en América Latina", dirigido por Hernán Ouviña (Instituto de Estudios de América Latina y el Caribe, Facultad de Ciencias Sociales, Universidad de Buenos Aires), e integrante del equipo "Niñez Plural" (Instituto de Ciencias Antropológicas, Facultad de Filosofía y Letras, Universidad de Buenos Aires). Educador popular de/con niñxs. santimorales07@gmail.com

\section{Ezequiel Retali}

Licenciado en Ciencia Política, Universidad de Buenos Aires. Estudiante avanzado de Filosofía (UBA). Educador popular de/con niñxs. ezequiel.retali@gmail.com 